\title{
Clinical value of lactate measurement and nucleated red blood cell counts in the placental segment of the umbilical vein of premature newborns for diagnosis of hypoxia-ischemia
}

\author{
Yvi Gea, ${ }^{1}$ Orlei Araujo, ${ }^{2}$ Luiz Vicente R. Silva ${ }^{3}$
}

\begin{abstract}
Objective: To evaluate the clinical value of lactate measurement and nucleated red blood cell (NRBC) counts when compared to base excess (BE) in the blood collected from the placental segment of the umbilical vein.

Methods: 25 umbilical cords from premature babies were sampled after placental delivery and cord clamping. Babies were followed until discharge. Statistics involved linear regression, Spearman's correlation, ROC curves, and Fisher's exact test.

Results: The relationship between lactate in the umbilical vein blood and $\mathrm{pH}$ and BE was significant $(\mathrm{p}<0.0001)$. A $4.04 \mathrm{mmol} / \mathrm{L}$ lactate level showed a sensitivity of $62.5 \%$ and a specificity of $94.1 \%$ in detecting $\mathrm{pH}<7.2$ and BE $<-10$ $\mathrm{mmol} / \mathrm{L}$. NRBC counts were related to BE $(p=0.0095)$, but with a sensitivity of $37.5 \%$ and specificity of $82.4 \%$ in detecting $\mathrm{BE}<-10 \mathrm{mmol} / \mathrm{L}$.

Conclusions: Lactate is a valuable marker of fetal hypoxia when sampled from placental segment veins. NRBC counts demonstrated low sensitivity for the detection of acidosis.
\end{abstract}

J Pediatr (Rio J). 2007;83(2):186-190: Lactate, erythroblasts, premature babies, fetal distress.

\section{Introduction}

Biochemical markers are valuable tools for the detection of hypoxic-ischemic events. Historically, fetal umbilical $\mathrm{pH}$ and base excess (BE) have been used as markers of hypoxic-ischemic insult, reflecting the cellular production of metabolic acids in consequence of hypoxemia. Lactate has been proposed as a useful method for the detection of fetal hypoxia. ${ }^{1}$ Nucleated red blood cell (NRBC) counts are increased in association with higher levels of erythropoietin in response to tissue hypoxia, and studies have demonstrated the relationship between this marker and perinatal hypoxia-ischemia. ${ }^{2,3}$ Both lactate and NRBC counts have been investigated as predictors of short and long-term prognosis, with conflicting results. ${ }^{1,4-6}$

The aim of this study was to evaluate lactate levels and NRBC counts in the blood from the placental segment of the umbilical vein of premature babies in relation to $B E$ values. We also investigated correlations of lactate and nucleated red blood cells to Apgar scores and maternal complications, and

1. Pediatra. Mestre, Faculdade de Ciências Médicas, Santa Casa de São Paulo, São Paulo, SP, Brasil. Serviço de Pediatria, Hospital e Maternidade Santa Marina, São Paulo, SP, Brasil.

2. Mestre, Universidade Federal de São Paulo - Escola Paulista de Medicina (UNIFESP-EPM), São Paulo, SP, Brasil. Coordenador, Serviço de Pediatria, Hospital e Maternidade Santa Marina, São Paulo, SP, Brasil.

3. Doutor. Professor, Departamento de Pediatria, Faculdade de Ciências Médicas, Santa Casa de São Paulo, São Paulo, SP, Brasil.

Manuscript received Jul 03 2006, accepted for publication Nov 142006.

Suggested citation: Gea Y, Araujo O, Silva LV. Clinical value of lactate measurement and nucleated red blood cell counts in the placental segment of the umbilical vein of premature newborns for diagnosis of hypoxia-ischemia. J Pediatr (Rio J). 2007;83(2):186-190.

doi 10.2223/JPED.1597 
prospectively followed these babies until hospital discharge, to assess the prognostic value of the markers with respect to the short-term outcome.

\section{Methods}

Twenty-five premature newborns, born at a tertiary hospital in Brazil, from April 2004 to January 2005, were assessed. Inclusion criteria were gestational age $<37$ weeks, weight $<2,000 \mathrm{~g}$, and a written informed consent signed by the mother. The study was approved by the local Research Ethics Committee. Congenital malformations, maternal diabetes and blood group incompatibility were exclusion criteria. Immediately after placental delivery, blood was sampled $(0.5 \mathrm{~mL})$ from the umbilical vein in the segment close to the placenta, using $5-\mathrm{mL}$ heparinized plastic syringes, and then placed on ice. Blood was also sampled into sodium fluoride vials for lactate measurements, and into K3-EDTA vials for blood cell counts. Analysis of blood gases was performed within 30 minutes after sampling, using a Rapid Lab 865 (Bayer) analyzer. Plasma lactate was analyzed by an enzymatic method (Ortho-Clinical Diagnostics - Vitros 750, Johnson \& Johnson). NRBC and leukocytes were counted through manual microscopy of the blood smear, and confirmed by a second technician. NRBC were calculated as the number of NRBC per 100 leukocytes.

Classically, acidosis at birth has been defined as BE in umbilical arterial blood lower than $-12 \mathrm{mmol} / \mathrm{L}$, which is approximately 2 standard deviations (SD) below the mean for normal newborns. ${ }^{7-9}$ Nodwell et al. demonstrated that values of blood gases are different in placental and umbilical segments after cord clamping and placental delivery. The values observed for $B E$ in the placental segment were -3.4 (mean) \pm 2.2 (SD). ${ }^{10}$ We defined our endpoint for acidosis as $B E$ equal to or lower than $-10 \mathrm{mmol} / \mathrm{L}$, which corresponds to 3 SD below the mean, based on these values.

For the short-term outcome we prospectively collected information about the occurrence of perinatal infection (defined by clinical signs and symptoms or positive blood culture, or both), periventricular or intraventricular hemorrhage (assessed by cranial ultrasound), necrotizing enterocolitis, need for vasoactive drugs, parenteral nutrition, blood products, oxygen, mechanical ventilation (invasive or non-invasive). Clinical information was also collected to calculate the Clinical Risk Index for Babies (CRIB) score in the first 12 hours of life. ${ }^{11}$ Lactate levels and NRBC correlations were investigated for each one of these factors. Apgar scores and maternal complications (infection, hypertensive disease, premature rupture of membranes more than 18 hours before birth) were also analyzed for relationships with the markers. Maternal infection was defined as the presence of fever, leukocytosis, or use of antibiotics for reasons such as urinary tract infection or pneumonia at birth. As neurological examination of premature babies is uncertain, this criterion was not included.

Statistical significance of correlations between investigated markers and $\mathrm{pH}, \mathrm{BE}, \mathrm{PCO}_{2}, \mathrm{O}_{2}$ saturation and oxygen blood content was determined by linear regression analysis with 99\% confidence intervals. For comparison between scores (Apgar and CRIB) and the markers, Spearman's non-parametric correlation was used. Through receiver operating characteristic (ROC) curves and contingency tables, we determined the value of the markers for identifying acidosis, and established the cutoff values for this parameter. We also tested the presence of a value higher than the defined cutoff values for the occurrence of perinatal outcome factors with Fisher's exact test. The statistical analysis was performed using the Analyse-it software (www.analyse-it. com).

\section{Results}

Clinical characteristics, perinatal events and their relationships to the investigated markers are shown in Table 1. Means and standard deviations were determined as follows: lactate $4.26 \pm 3.78 \mathrm{mmol} / \mathrm{L}$; NRBC counts $20.52 \pm$ 37.96 cells/100 leukocytes; $B E,-9.35 \pm 5.99 \mathrm{mmol} / \mathrm{L} ; \mathrm{pH}$, $7.22 \pm 0.17 ; \mathrm{CO}_{2}, 46.06 \pm 17.74 \mathrm{mmHg}$. Figure 1 shows the correlation between umbilical vein blood values of lactate and $B E\left(R^{2}=0.72, p<0.0001\right)$. For the identification of acidosis $(B E<-10 \mathrm{mmol} / \mathrm{L})$, the area under the ROC curve was 0.842 . The sensitivity of a lactate cutoff level equal to $4.04 \mathrm{mmol} / \mathrm{L}$ in relation to $B E$ lower than or equal to $-10 \mathrm{mmol} / \mathrm{L}$ was $62.5 \%$, and specificity was $94.1 \%$, with a positive predictive value equal to $83.3 \%$, and negative predictive value of $84.2 \%$. The same values were observed for $\mathrm{pH}$. Although $\mathrm{pH}$ and $\mathrm{CO}_{2}$ were not endpoints, because of their variability caused by placental metabolism and gas exchange after cord clamping, we observed a strong relationship between lactate and $\mathrm{pH}$ $\left(R^{2}=0.82, p<0.0001\right)$, and between lactate and $\mathrm{PCO}_{2}$ $\left(R^{2}=0.6, p<0.0001\right)$. There was a weak correlation between lactate and bicarbonate $\left(R^{2}=0.23, p=0.014\right)$, and no correlation was found between lactate and $\mathrm{O}_{2}$ blood content, $\mathrm{PO}_{2}$ and hemoglobin oxygen saturation, and Apgar scores. Apgar scores were also not related to $\mathrm{pH}$ and $\mathrm{BE}$.

NRBC counts were related to $B E\left(R^{2}=0.26, p=0.009\right)$ and to $\mathrm{pH}\left(\mathrm{R}^{2}=0.38, \mathrm{p}=0.009\right)$. A cutoff value of $10 \mathrm{NRBC} / 100$ leukocytes showed poor sensitivity (40\%) and specificity of $80 \%$ for more severe acidosis (BE lower than $-12 \mathrm{mmol} / \mathrm{L}$ ). For our endpoint (BE lower than $-10 \mathrm{mmol} / \mathrm{L}$ ), NRBC count was not an adequate test, with an area under the ROC curve equal to $0.577(p=0.26)$, sensitivity of $37.5 \%$ and specificity of $82.4 \%$, positive predictive value equal to $50 \%$ and negative predictive value equal to $73.6 \%$. The area under the ROC curve was 0.87 for the determination of $\mathrm{pH}<7.2$, for 
the cutoff value of NRBC, with sensitivity of $50 \%$ and specificity of $88.2 \%$. NRBC were not correlated to blood oxygen content and $\mathrm{PO}_{2}$ and showed a weak correlation to oxygen saturation $\left(R^{2}=0.07, p=0.018\right)$ and $\mathrm{PCO}_{2}$ $\left(R^{2}=0.33, p=0.0027\right)$. NRBC count and lactate levels were related to each other $\left(R^{2}=0.4, p=0.0008\right)$, and NRBC count also showed weak correlation to Apgar scores ( $p=0.03$ at 1 minute and $p=0.02$ at 5 minutes).

Both lactate levels and NRBC count were unable to predict short-term perinatal complications, with an exception: from the seven babies with NRBC counts equal to or higher than $10 / 100$ leukocytes, three developed necrotizing enterocolitis
$(42 \%, p=0.026)$, with one intestinal perforation. Lactate levels and NRBC counts were not related to maternal complications.

\section{Discussion}

The diagnosis of hypoxia-ischemia at birth is critical, and combining clinical markers with laboratory data would be useful to identify premature infants with higher risk for neurological damage. ${ }^{4}$

Samples from the umbilical artery may be limited by small volume and by the difficulty in collecting them, especially in thin umbilical cords. The umbilical vein, close to the site of

Table 1 - Characteristics of patients, perinatal events and their relationships to lactate levels and NRBC counts

\begin{tabular}{|c|c|c|c|}
\hline & & $\begin{array}{l}\text { Relationship } \\
\text { to lactate }\end{array}$ & $\begin{array}{l}\text { Relationship } \\
\text { to NRBC }\end{array}$ \\
\hline $\begin{array}{l}\text { Gestational age (weeks, mean } \pm S D \text {, minimum, } \\
\text { maximum) }\end{array}$ & $\begin{array}{l}33.57 \pm 1.98 \\
(29-36.8)\end{array}$ & NS* & NS* \\
\hline Gender (male/ female ratio) & $15 / 10$ & $\mathrm{NS}^{+}$ & $\mathrm{NS}^{+}$ \\
\hline Apgar score at 1 min (median, min, max) & $8(1-9)$ & NS* & $\begin{array}{c}p=0.029 \\
(R S=-0.41)\end{array}$ \\
\hline Apgar score at 5 min (median, min, max) & $9(7-10)$ & NS* & $\begin{array}{c}p=0.002 \\
(R S=-0.53)\end{array}$ \\
\hline Birth weight ( $\mathrm{kg}$, mean $\pm \mathrm{SD}$, min, max) & $\begin{array}{c}1.701 \pm 0.233 \\
(1.075-2.000)\end{array}$ & NS* & NS* \\
\hline CRIB score (median, min, max) & $4(1-12)$ & NS* & NS* \\
\hline Maternal infection (ratio and \%) & $9 / 25(36 \%)$ & $\mathrm{NS}^{+}$ & $\mathrm{NS}^{+}$ \\
\hline Maternal hypertensive disease (ratio and \%) & $6 / 25(24 \%)$ & $\mathrm{NS}^{+}$ & $\mathrm{NS}^{+}$ \\
\hline $\begin{array}{l}\text { Premature rupture of membranes more than } 18 \text { hours } \\
(\text { ratio, \%) }\end{array}$ & $10 / 25(40 \%)$ & $\mathrm{NS}^{+}$ & $\mathrm{NS}^{+}$ \\
\hline Perinatal infection (ratio and \%) & $13 / 25(52 \%)$ & $\mathrm{NS}^{+}$ & $\mathrm{NS}^{+}$ \\
\hline Need for blood products & $10 / 25(40 \%)$ & $\mathrm{NS}^{+}$ & $\mathrm{NS}^{+}$ \\
\hline Need for invasive mechanical ventilation & $9 / 25(36 \%)$ & $\mathrm{NS}^{+}$ & $\mathrm{NS}^{+}$ \\
\hline Need for parenteral nutrition & $5 / 26(19.2 \%)$ & $\mathrm{NS}^{+}$ & $\mathrm{NS}^{+}$ \\
\hline Need for vasoactive drugs (ratio and \%) & $10 / 25(40 \%)$ & $\mathrm{NS}^{+}$ & $\mathrm{NS}^{+}$ \\
\hline $\begin{array}{l}\text { Necrotizing enterocolitis (grade } 2 \text { or higher according } \\
\text { to Bell's classification, ratio and \%) }\end{array}$ & $3 / 25(12 \%)$ & $\mathrm{NS}^{+}$ & $\mathrm{p}=0.026^{+}$ \\
\hline $\begin{array}{l}\text { Periventricular or ventricular hemorrhage } \\
\text { (grade I to IV, ratio and \%) }\end{array}$ & $5 / 25(20 \%)$ & $\mathrm{NS}^{+}$ & $\mathrm{NS}^{+}$ \\
\hline
\end{tabular}

NS = non-significant; RS = Spearman's correlation coefficient.

* Spearman's non-parametric correlation.

† Fisher's exact test. 


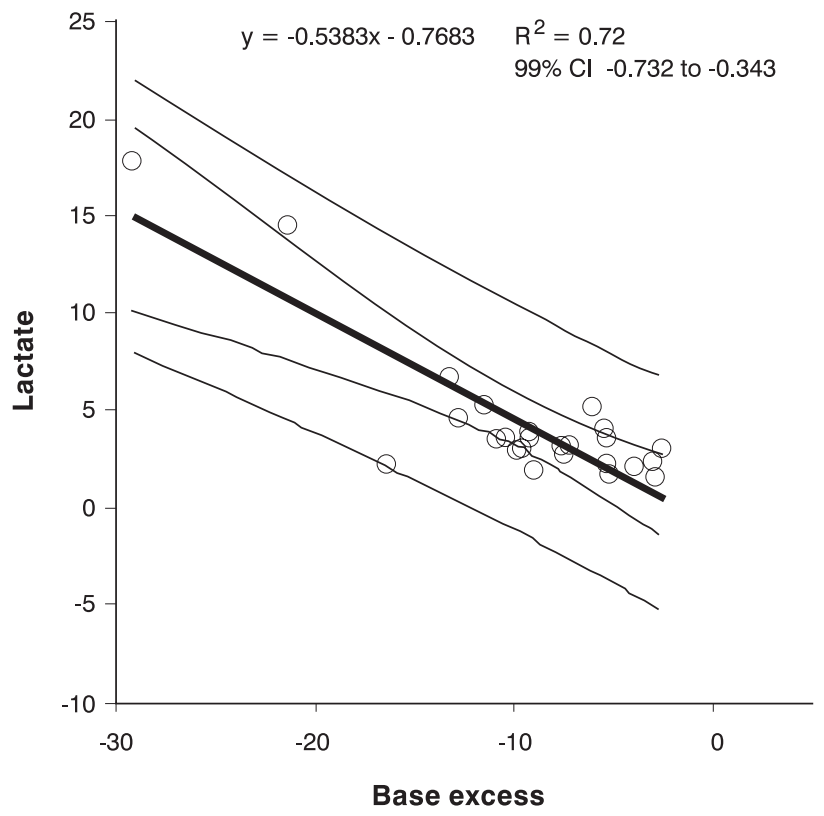

Figure 1 - Correlation between lactate and BE $\mathrm{CI}=$ confidence interval; $\mathrm{R}^{2}=$ linear regression correlation coefficient; $y=$ slope coefficient

placental insertion, can provide an alternative source for sampling, but only after placental delivery. Placental metabolism and gas exchange proceed after delivery and cord clamping, affecting measurements in vein blood. This is particularly true for oxygen measurements and $\mathrm{PCO}_{2}$, but Nodwel et al. demonstrated that the agreement between $\mathrm{BE}$ in blood from the placental segment of the umbilical vein, and in blood from the umbilical segment of the umbilical vein or artery, is acceptable for clinical purposes. ${ }^{10}$ We observed that in blood from the placental segment of the umbilical vein after placental delivery, lactate maintains the same good correlation to $\mathrm{BE}$ previously reported for arterial measurements. ${ }^{1}$ Thus, lactate has a potential as a simple and inexpensive tool for the diagnosis of metabolic acidosis associated with hypoxia-ischemia in premature infants. A whole blood gas analysis costs nearly three times more than a single lactate measurement.

Elevated NRBC counts in umbilical venous blood have been correlated to acute and chronic antepartum asphyxia. ${ }^{12}$ Maternal nucleated blood cells can transfer into fetal circulation when uteroplacental perfusion is impaired, but this is not significant for counts (one maternal cell to at least 100 fetal cells). ${ }^{13}$ NRBC counts in placental circulation are also correlated to counts in umbilical blood. ${ }^{14}$ These facts, coupled with the assumption that NRBC count in umbilical vein blood is not influenced by placental metabolism and cord clamping, make it attractive as one more tool for monitoring the condition of premature newborns. We found that NRBC counts are weakly related to $\mathrm{BE}$ and $\mathrm{pH}$, with low sensitivity and positive predictive values. NRBC count cannot be recommended for routine clinical diagnosis of perinatal acidosis, since classical markers and lactate measurements are more adequate.

Neither lactate nor NRBC counts were useful to predict the short-term outcome as single markers. Cases of necrotizing enterocolitis with elevated NRBC counts have been previously reported, ${ }^{15}$ suggesting that NRBC counts in premature infants can help to identify risk groups. More prospective studies are needed.

\section{References}

1. da Silva S, Hennebert N, Denis R, Wayenberg JL. Clinical value of a single postnatal lactate measurement after intrapartum asphyxia. Acta Paediatr. 2000;89:320-3.

2. Hermansen MC. Nucleated red blood cells in the fetus and newborn. Arch Dis Child Fetal Neonatal Ed. 2001;84:F211-5.

3. Schaefer M, Rowan RM. The clinical relevance of nucleated red blood cell counts. Sysmex J Int. 2000;10:59-63.

4. Perlman JM, Risser R. Can asphyxiated infants at risk for neonatal seizures be rapidly identified by current high-risk markers? Pediatrics. 1996;97:456-62.

5. Korst LM, Phelan JP, Ahn MO, Martin GI. Nucleated red blood cells: an update on the marker for fetal asphyxia. Am J Obstet Gynecol. 1996;175:843-6.

6. Buonocore G, Perrone S, Gioia D, Gatti MG, Massafra C, Agosta $R$, et al. Nucleated red blood cell count at birth as an index of perinatal brain damage. Am J Obstet Gynecol. 1999;181:1500-5.

7. Ross MG, Gala R. Use of umbilical artery base excess: algorithm for the timing of hypoxic injury. Am J Obstet Gynecol. 2002;187:1-9.

8. Chanrachakul B, Chua S, Nordstom L, Yam J, Arulkumaran S. Umbilical artery blood gas and lactate in healthy newborns. J Med Assoc Thai. 1999;82:388-93.

9. Helwig JT, Parer JT, Kilpatrick SJ, Laros RK Jr. Umbilical cord blood acid-base status: what is normal? Am J Obstet Gynecol. 1996; 174:1807-12.

10. Nodwell A, Carmichael L, Ross M, Richardson B. Placental compared with umbilical cord blood to assess fetal blood gas and acid-base status. Obstet Gynecol. 2005;105:129-38.

11. The CRIB (clinical risk index for babies) score: a tool for assessing initial neonatal risk and comparing performance of neonatal intensive care units. The International Neonatal Network. Lancet. 1993;342:193-8.

12. Ghosh B, Mittal S, Kumar S, Dadhwal V. Prediction of perinatal asphyxia with nucleated red blood cells in cord blood of newborns. Int J Gynaecol Obstet. 2003;81:267-71.

13. Lo YM, Lo ES, Watson N, Noakes L, Sargent IL, Thilaganathan B, et al. Two-way cell traffic between mother and fetus: biologic and clinical implications. Blood. 1996;88:4390-5. 
14. Akyol D, Hajdu C, Ferber A, O'reilly-Green C, Giancotti FR, Dorsett $\mathrm{BH}$, et al. Fine-needle aspiration in the evaluation of nucleated red blood cells in the human placenta. Am J Obstet Gynecol. 2003;189:155-8.

15. Mandel D, Lubetzky R, Mimouni FB, Cohen S, Littner Y, Deutsch $\mathrm{V}$, et al. Nucleated red blood cells in preterm infants who have necrotizing enterocolitis. J Pediatr. 2004;144:653-5.
Correspondence:

Orlei Araujo

Alameda Rio Claro, 95/74, Bela Vista CEP 01332-010 - São Paulo, SP - Brazil

Tel. : +55 (11) 5084.4844, +55 (11) 9404.5905

Fax: +55 (11) 5563.9331, +55 (11) 5084.4844

E-mail: orlei@uol.com.br 